\title{
El vasquismo espiritual de Eladio Esparza
}

\section{Eladio Esparza's Spiritual Basquism}

\section{FERnando Mikelarena PeÑA}

Universidad de Zaragoza

Facultad de Empresa y Gestión Pública

Departamento de Ciencias de la Documentación e Historia de la Ciencia

Plaza de la Constitución, I

2200 I Huesca (España)

fmikelar@unizar.es

Resumen: En este artículo se analiza el vasquismo de Eladio Esparza en sus colaboraciones en la prensa: en Diario de Navarra entre 1910 y 1923 y entre 1929 y 1952, en El Pensamiento Navarro en 1911. en La Voz de Navarra entre 1923 y 1927, y en Euzkadi entre 1925 y 1929. Su figura es importante por su condición de vascoparlante nativo, por su evolución ideológica -ya que, tras dirigir el periódico nacionalista La Voz de Navarra y colaborar con Euzkadi, fue el principal formulador del navarrismo foralcatólico desde las páginas de Diario de Navarra del que fue subdirector desde 1930-y por sus tesis a partir de 1929 en pro de un vasquismo espiritual y en contra del vasquismo político, también presentes en su novela La Dama del Lebrel Blanco.

Palabras clave: Vasquismo. Euskera. Nacionalismo vasco. Navarrismo. Navarra. Eladio Esparza.

Abstract: This article analyses Eladio Esparza's Basquism. Those opinions were published in multiple papers, such as, Diario de Navarra from 1910 to 1923 and from 1929 to 1952, El Pensamiento Navarro in 191 I, La Voz de Navarra from 1923 to 1927 and Euzkadifrom 1925 to 1929. In addition to being a native Basque speaker, his ideological evolution makes Eladio Esparza a particularly relevant figure. After directing the nationalist paper La Voz de Navarra and closely collaborating with Euzkadi, Eladio Esparza was the main formulator of foral-catholic navarrism in Diario de Navarra. His thesis in favour of spiritual Basquism and against a political Basquism, present in his novel La Dama del Lebrel Blanco are also relevant.

Keywords: Basquism. Basque Language. Basque Nationalism. «Navarrismo». Navarre. Eladio Esparza. 
Conocidas las líneas generales de los vínculos entre navarrismo y vasquismo entre 1841 y 19361, en este artículo se analiza la evolución del vasquismo de Eladio Esparza entre 1910 y 1952 a través de sus colaboraciones en la prensa, primordialmente en Diario de Navarra entre 1910 y 1923 y entre 1929 y 1952. Vascoparlante nativo, su vasquismo de los primeros años incluía reticencias a las posiciones del nacionalismo vasco ortodoxo, pese a lo cual se le encargó la dirección del órgano nacionalista La Voz de Navarra entre 1923 y 1925 y fue columnista del mismo hasta 1927 y del diario Euzkadi entre 1925 y 1929. De nuevo en Diario de Navarra desde 1929, periódico del que fue subdirector desde 1930, defendió en el mismo un vasquismo espiritual y en contra del vasquismo político, algo también muy vivo en su novela La Dama del Lebrel Blanco. Esa postura, junto a otras en relación con la relación del Estado y con la unión vasconavarra y con los cimientos del autogobierno navarro, le convierte en el teórico principal del navarrismo foralcatólico, algo no suficientemente remarcado por los especialistas.

\section{SITUACIÓN DE LA LENGUA VASCA EN NAVARRA}

Antes de seguir es importante señalar la situación de la lengua vasca en Navarra en la época estudiada. Entre 1863 y los años treinta del siglo XX, el número de vascoparlantes en Navarra había descendido de unos 90000 - que representaban el $30 \%$ de la población total y que se situaban por toda la Merindad de Pamplona, llegando por el sur hasta la Valdorba y alcanzando por el este la mayor parte de los valles pirenaicos- a unas 61000 personas, el 17 por ciento del total, localizados al norte de una línea que corría desde la Burunda al Roncal, pasando por Ergoyena, Araquil, Juslapeña, Esteríbar, Egüés, Arce, Urraúl Alto y Salazar. Ahora bien, según los datos aportados por Irigaray sobre el conocimiento y uso del idioma por grupos de edades en 1935, en el valle del Roncal y en muchos o algunos pueblos de los valles de Salazar, Aézcoa, Erro, Esteríbar, Anué, Atez, Odieta, Olaibar, Ulzama, Gulina y Araquil el euskera era hablado solo por los tramos de edades superiores².

Obviamente, el escaso número de los vascohablantes dentro del contexto navarro, así como su ubicación en entornos rurales de la Montaña, suponía un claro obstáculo para aquellas ideologías identitarias como el nacionalismo vasco que hacían de la lengua vasca un eje central de su discurso de conformación comunitaria. Si bien, en ocasiones, la defensa de un idioma autóctono minoritario no es un elemento absolutamente determinante para la extensión de un mensaje

\footnotetext{
I García-Sanz Marcotegui, Iriarte López y Mikelarena Peña, 2002; Iriarte López, 2000.

${ }^{2}$ Erize, 1997. 


\section{EL VASQUISMO ESPIRITUAL DE ELADIO ESPARZA}

identitario asociado con un ideario nacionalista, en el caso de Navarra sí que pudo ser un elemento altamente condicionante para el desarrollo del nacionalismo vasco, cuyo nivel de voto en la Segunda República se limitaba al $9 \%$, aun cuando en ello también intervinieran otros factores. En este sentido, el caso navarro recuerda al valenciano en relación con el cual Fuster ${ }^{3}$ comentó que las reivindicaciones lingüísticas de la zona catalanoparlante no eran compartidas, e incluso eran rechazadas, por la zona castellanoparlante, teniendo efectos políticos. De cualquier forma, en aquel entonces, los vascoparlantes navarros no constituían una comunidad lingüística articulada en el sentido de exigir la satisfacción de sus derechos idiomáticos, y tampoco se reconocían como comunidad política al no identificarse con unas formaciones políticas determinadas de signo nacionalista. De hecho, en la montaña vascoparlante la fuerza más votada era el carlismo, habiendo durante la República poquísimos municipios en esa zona en la que el PNV llegara a ser el partido más votado. Asimismo, no hay que olvidar que, para ser reivindicado de forma plena como elemento identitario, el euskara se enfrentaba con el inconveniente de su no estandarización y de su fragmentación dialectal.

De cualquier forma, todo lo anterior no se contradice con el hecho de que numerosas personalidades, por lo general no vascoparlantes, de la derecha tradicionalista y conservadora no nacionalista se caracterizaran por una profunda vascofilia, si bien, por lo general, de índole retórica. Ese fenómeno, analizado en las monografías de García-Sanz Marcotegui, Iriarte López y Mikelarena y de Iriarte López $^{4}$, también era posible porque la lengua vasca, al no estar estandarizada y no tener detrás una comunidad lingüística consciente, idiomáticamente reivindicativa, no planteaba ninguna fricción en el campo político porque no se planteaba su empleo en la enseñanza o en la administración -aunque sí lo hicieron los fracasados textos estatutarios de 1931-1932, que lo habrían oficializado en las áreas vascoparlantes, como veremos- y porque tampoco se interpretaba como un elemento que ayudara a una fácil penetración del nacionalismo vasco.

\section{El VAsQuismo del primer Eladio Esparza. De 1910 a 1923.}

Eladio Esparza Aguinaga nació en Lesaka, en el noroeste de Navarra, en la comarca de Bortziriak o Cinco Villas, en $1888^{5}$. Su padre, originario de Tierra Estella, era secretario municipal de la localidad desde 1878.

\footnotetext{
${ }^{3}$ Fuster, 1967, pp. II4-II5.

${ }^{4}$ García-Sanz Marcotegui, Iriarte López y Mikelarena Peña, 2002; Iriarte López, 2000.

${ }^{5}$ Archivo Municipal de Lesaka (AML), Caja 108/5, Padrón 1905.
} 
A finales del siglo XIX y comienzos del XX la estructura económica de Lesaka era estrictamente agropecuaria, con una fuerte incidencia de la emigración y escasa población foránea, ya que incluso el número de carabineros y de guardias civiles era exiguo ${ }^{6}$. La localidad era marcadamente vascoparlante siendo el euskera conocido y utilizado por la práctica totalidad de la población en aquella época en la vida diaria, tal y como reseñó el periodista Manuel Aznar en relación con su pueblo natal, Etxalar, colindante a Lesaka, en un artículo publicado en Euzkadi el 10 de octubre de 19/4. El apego a las tradiciones populares también era muy amplio: fue uno de los pocos pueblos en los que siempre se mantuvo la tradición del Olentzero ${ }^{7}$. Criado en este ambiente, Eladio Esparza era vascoparlante nativo, a pesar de que la práctica totalidad de su producción literaria y periodística $^{8}$ la desarrolló en lengua castellana.

Después de estudiar en el Seminario de San Miguel de Pamplona desde 1901 - con notas de meritissimus en casi todas las asignaturas-9, en 1910 decidió abandonarlo ${ }^{10}$. Ese año colaboraría de forma estable en Diario de Navarra con el seudónimo de Javier de Miranda" con una serie de artículos, la mayoría de naturaleza literaria. Ese seudónimo sería el que emplearía en sus colaboraciones en dicho periódico hasta junio de 1922, momento desde el que firmaría con su nombre y apellido.

En enero de 19II trabajó como redactor en El Pensamiento Navarro, publicando con regularidad, durante algunos meses, artículos literarios intrascendentes con el seudónimo de Ramuncho ${ }^{12}$. Al poco, regresó a su pueblo natal para casarse con la maestra de la localidad, Ramona Viela. Desde Lesaka retomaría sus colaboraciones con Diario de Navarra con el seudónimo antes citado, así como sus labores de novelista y dramaturgo. El 17 de diciembre de 191I Raimundo García, Garcilaso se refería en Diario de Navarra a su amistad con él y a su existencia entre libros. Continuó residiendo en Lesaka hasta que en abril de 1923 se trasladó a Pamplona para hacerse cargo de la dirección del periódico nacionalista

\footnotetext{
${ }^{6}$ Erdozáin y Mikelarena, 2003.

${ }^{7}$ Mikelarena, 2007.

${ }^{8}$ Aznar Munárriz, 2021.

9 Archivo Seminario Pamplona (ASP), Libro de prueba de los alumnos del Seminario Conciliar de San Miguel de Pamplona (1902-1923), cursos citados. Agradezco a Miguel Larrambebere su amabilidad al facilitarme el acceso a dicha información.

${ }^{10}$ Datos biográficos sobre Eladio Esparza en la Gran Enciclopedia de Navarra [En línea].

" La identificación de ese seudónimo con Eladio Esparza en Napartarra el II de octubre de 1913, en un artículo del Padre Fabo publicado en Diario de Navarra el 27 de agosto de 1916 y en otro artículo del mismo periódico de 15 de octubre de 1917.

12 Ese dato fue publicado en su necrológica en Diario de Navarra el 25 de marzo de 1961. Asimismo, El Correo Español de 23 de enero y de 4 de febrero de 1911 informó de su incorporación a El Pensamiento Navarro.
} 


\section{EL VASQUISMO ESPIRITUAL DE ELADIO ESPARZA}

La Voz de Navarra. Simultaneó sus quehaceres literarios desde septiembre de 1917 con el cargo de secretario municipal de la localidad, sucediendo en el mismo a su padre ${ }^{13}$, hasta su dimisión del mismo el 23 de mayo de 1921, sin explicitarse los motivos ni en el libro de actas ni en la carta de dimisión ${ }^{14}$.

En aquellos primeros años diez, en los que tradicionalistas y nacionalistas polemizaron arduamente en su prensa — sobre todo desde las páginas de El Pensamiento Navarro y del semanario Napartarra- con motivo de la aparición de los segundos como competidores electorales de los primeros, Esparza trató de mantenerse al margen de los debates. Ello motivó que desde el semanario nacionalista Napartarra se le requiriera el 20 de septiembre de 1913 que diera explicaciones sobre su propio punto de vista en relación con el nacionalismo por las críticas al mismo que dos días antes, en un artículo en Diario de Navarra, había puesto en boca de un viajero. El lesakarra replicó en un artículo del 5 de octubre en el que planteaba la conveniencia de un nacionalismo abierto e incluyente. A su juicio, el PNV, «en vez de ser savia opulenta en un tronco viejo, se ha metido en él como una cuña de acero tajante», «repartiendo mandobles, en vez de sembrar esperanzas». Dicho partido debía «ser una excitación generosa, un criterio amplio, una llamarada inmensa, un arco de alianza sobre todos los que han nacido en el mismo suelo y sienten el cariño de la Patria».

Esa respuesta no fue del agrado del órgano nacionalista que el II de octubre de 1913 se refería a Esparza por su nombre, defendiendo que la finalidad del nacionalismo vasco era salvar y magnificar a la patria vasca desde un enfoque católico, ideal que suponía compartía el lesakarra. La insatisfacción de los peneuvistas con él se volvió a traslucir una semana después: el 18 de octubre de 1913 un tal $A$. publicaba una crítica durísima a su novela Tierra que florece.

No obstante, parece que la ofuscación de algunos nacionalistas con Esparza remitió posteriormente. El 16 de enero de 1916 en la sección dominical Euzkarazko saila que Diario de Navarra dedicó a colaboraciones en euskera durante aquellos años, José Agerre Santesteban, coordinador de la misma, que en 1913 era secretario del Centro Vasco y que en 1918 se haría cargo de la dirección de Napartarra ${ }^{15}$, dedicó a Esparza, que había nacido el mismo año que él y con el que coincidió en el Seminario, un artículo laudatorio titulado «Gazte gaztetarik adizkide zaitut» - es decir, «Te tengo por compañero desde que éramos jóvenes»que suscitó el agradecimiento del aludido. No obstante, una semana después, el

\footnotetext{
${ }^{13}$ El nombramiento como secretario interino el 30 de septiembre de 1917 en AML, Libro 24, Libro de actas de Pleno, 1914-1917, fol.173v-174; El nombramiento como secretario titular el 14 de octubre en fol. 175v-176. ${ }^{14}$ AML, Libro 25, Libro de Actas de Pleno, 1918-1923, f.ol I59v; AML, Caja 82, 14.

${ }^{15}$ Chueca, 1989, p. 92.
} 


\section{FERNANDO MIKELARENA PEÑA}

23 de enero, Agerre reconvenía a Esparza sobre sus deudas con su lengua materna.

En el verano de 1916 Esparza haría expresión de fe en el vasquismo y en el Renacimiento cultural vasco, pero añadiendo unas notas de escepticismo y de exigencia de profundidad que reaparecerán a finales de los años veinte. Al hilo de una fiesta celebrada en el colegio de Lecároz, hará pública el 4 de julio de aquel año su simpatía por la expresión vitalista que suponen los bailes, la música y la lengua vascas, rasgos peculiares todos ellos «de nuestra raza». Con todo, aunque el 2 de agosto, refiriéndose a las fiestas vaskas celebradas en Elizondo manifestará su apoyo a las mismas como con «todo lo que se oriente» a «vigorizar el nervio de la raza» que «está sufriendo una formidable tisis ósea», al mismo tiempo criticará la «faramalla» existente alrededor, «ese vasquismo de guante blanco»: hacía falta celebrar dichas fiestas, pero «con plena conciencia», «porque en las fiestas hay mucho de sprit de deleite estético, de lucimiento personal» y eso «es contraproducente» ya que aquellas, para que «dejen un algo positivo, un rastro social, deben influir de tal manera» con el fin de que en la gente nazca «un fuerte amor a lo suyo. El amor irá despertando la conciencia y todas las demás cosas se les darán por añadidura».

Al mes siguiente, el 3 de septiembre, en otro artículo sobre un folleto sobre la Editorial Pizkundia -es decir, Renacimiento en castellano- impulsada por la Juventud Vasca de Bilbao señalará que, a pesar de la presencia en el proyecto de «nombres prestigiosos del partido nacionalista», no había que alegar reparos por ello porque «aquí no hay política», dada la importancia de que

la raza, la lengua, las leyendas, la historia, la poesía, la legislación, todo cuanto es genuinamente nuestro y reside en el alma misma de la raza, todo cuando suponga un alto valor vasko, sea revisado y puesto en circulación por los hombres de pluma que aman a su patria.

No podía haber disconformidad en relación con esa iniciativa que perseguía «purificar la sangre de un corazón que se ama y restaurar las viejas paredes del alcázar de nuestros sueños». Como «la luz ha de preceder» a «un movimiento de conciencia y de voluntad», «así tendremos Patria, al tener conquistados el cultivo de nuestra inteligencia y la educación de nuestro sentimiento porque la conoceremos y la amaremos».

Dos años más tarde, Esparza expresará su conformidad con las tesis recogidas por Jesús de Sarriá en su libro Ideología del nacionalismo vasco. El 16 de junio de 1918 en Diario de Navarra formulará su apoyo al nacionalismo vasco en expansión y al Renacimiento Vasco, previniendo, no obstante, ante la circunstancia de que personas oficialmente no nacionalistas, e incluso antinacionalistas, también acogían «con calurosa simpatía este renacer lozano del vasquismo y prestan su apoyo y colaboran en la obra y propagan la idea y se sienten orgullosos de ser 


\section{EL VASQUISMO ESPIRITUAL DE ELADIO ESPARZA}

vascos». A su juicio, los nacionalistas tenían que hacer frente a ese hecho, generado en última instancia por la relación con España, que, a su juicio, era resuelta de forma convincente por Sarría al explicar, el día 24 y el 30, que este autor combinaba el soberanismo con una acepción de la patria asentada «en la emoción nacional» y con un planteamiento de un nuevo estado ibérico con pleno reconocimiento de las nacionalidades constituidas como estados federados con «un criterio nacionalista en el que España no se odia, ni se desgarra, ni se pisotea. Es decir, un nacionalismo que no es separatista».

A fin de año Esparza fomentará desde su cargo de secretario municipal el movimiento reintegracionista ${ }^{16}$ en su comarca, dirigiéndose a los asistentes en la asamblea de Lesaka de 15 de diciembre con un discurso, publicado íntegramente en El Pueblo Navarro los días 17 y 18 de diciembre, en el que defendió la reintegración foral ${ }^{17}$.

Tras el fracaso de aquel movimiento Esparza no publicará ningún artículo más en su plataforma de Diario de Navarra sobre nacionalismo o sobre vasquismo.

\section{ELADIO ESPARZA EN LA ÉPOCA DE DIRECTOR DE LA VOZ DE NAVARRA Y DE COLABORADOR EN EL DIARIO EUZKADI (1923-1929)}

Esparza fue designado en la primavera de 1923 primer director de La Voz de Navarra, el periódico fomentado por el nacionalismo vasco y en cuyo accionariado figuraban nombres de destacados nacionalistas como Manuel de Aranzadi, Joaquín y Javier San Julián, Manuel Zarranz, Leopoldo Garmendia, Manuel de Irujo, Serapio Esparza, etc. ${ }^{18}$. Cobraba 6000 pesetas anuales, mil pesetas más de las que cobraba Raimundo García, Garcilaso, su homólogo en Diario de Navarra ${ }^{19}$. A la altura de 1923 la tirada de La Voz de Navarra era de 5000 ejemplares, por 8500 de Diario de Navarra, 2300 de El Pueblo Navarro y 2000 de El Pensamiento Navarro $^{20}$.

Esparza ostentaría tal cargo hasta el I de febrero de 192521. Algo más de un año antes, el 29 de diciembre de 1923, había sido detenido junto con el subdirector y cinco redactores, según informó el periódico el I de enero de 1924,

\footnotetext{
16 Mikelarena, 2019.

17 Jimeno Jurío, 2008, pp. 245-253.

18 Osés Larumbe, 1988, p. 416.

19 Osés Larumbe, 1988, p. 417.

20 Moreda de Lecea, 1992, p. 573. Los datos proceden del registro sobre la riqueza imponible del Archivo de la Diputación. En 1928 La Voz de Navarra y El Pensamiento Navarro tendrían la misma tirada, mientras que la de Diario de Navarra ascendía a los 10000 ejemplares y la de El Pueblo Navarro bajaba a los 1400.

${ }^{21}$ Guía de Navarra, 1926, p. 34.
} 


\section{FERNANDO MIKELARENA PEÑA}

y conducido al Gobierno Civil y más tarde a la cárcel de Pamplona donde quedaron a disposición del Juzgado Militar por reproducir un telegrama de Le Matin sobre la guerra de Marruecos, siendo liberado días después ${ }^{22}$. Finalmente, según informaba Diario de Navarra de 12 de abril de 1924, su caso fue sobreseído.

Curiosamente, en nuestro repaso de los textos firmados por Eladio Esparza en el periódico del que era director, por lo general en la sección titulada Interpretaciones, hemos advertido que se limitaron en su mayoría a ser divagaciones filosófico-literarias, sin reflejarse posicionamientos claros de la hipotética ideología nacionalista del autor ni tampoco su vasquismo. Lo mismo sucedió en sus columnas en la misma sección tras su salida como director.

En marzo de 1925 Esparza regresó a la secretaría del ayuntamiento de Lesaka, primero de forma interina ${ }^{23}$, en propiedad dos meses después ${ }^{24}$.

A partir de entonces también publicó colaboraciones en el diario Euzkadi, primero de forma esporádica, y más habituales a partir de 1927, casi siempre en primera plana y con su firma. Sin embargo, la mayoría fueron de carácter literario, filosófico, religioso o histórico, de escasa enjundia, por lo general, bajo la sección Glosario. Su vasquismo traslució en pocas ocasiones, como cuando ensalzó a escritores euskéricos como el poeta José de Arregi por sus traducciones de Heine (el 17 de enero de 1928) o como Kirikiño, tras cuyo fallecimiento publicó un sentido texto de homenaje el 6 de febrero de 1929 por su trabajo en pro del euskera, comentando su relación personal con él.

En otros artículos, por contra, deslizó un cambio de perspectiva que presagian los contenidos de su novela La Dama del Lebrel Blanco y los derroteros de sus colaboraciones posteriores en Diario de Navarra a partir de la primavera de 1929.

El 7 de junio de 1928 publicó una colaboración con ocasión de un artículo de Bonifacio de Echegaray en la que sostenía que una hipotética política lingüística que obligara a los habitantes de Vasconia a hablar en euskera fracasaría porque «el problema de la lengua es un problema originariamente sentimental (...)» ya que el vasco debe sentir «en lo profundo de su alma el fuerte deseo de hablar su lengua natal, la profunda ansia de pulirla». «El problema, pues, del alma vasca es un caso de conciencia que debe resolverlo cada uno con una sincera y honda lealtad», no solventándose «con pasquines, ni con manifiestos, ni con política». Así, coincidía con Echegaray en

\footnotetext{
22 Guía de Navarra, 1926, p. 5.

${ }^{23}$ AML, Libro 26, Libro de Actas de Pleno, 1923-1931, fol. 67r-67v.

${ }^{24}$ AML, Libro 26, Libro de Actas de Pleno, 1923-1931, fol. 68r.
} 


\section{EL VASQUISMO ESPIRITUAL DE ELADIO ESPARZA}

que la lengua no puede ni debe ser patrimonio de grupos, ni de escuelas ni de partidos. Es el patrimonio de todos los vascos, venido a lamentable merma en el siglo pasado por culpa de los vascos. Hoy, por impulso también de los vascos, se trata de mejorarlo, de rescatarlo, de librarlo de hipotecas ingratas, de bruñirlo y prestarle movimiento. Pues el que se sienta vasco debe estar donde están esos operarios meritorios y constantes.

Como conocedor «de lo que sean alma vasca, lengua vasca y pueblo», Esparza creía «que es necesario decir las cosas con lealtad».

Otros textos se refieren al problema navarro dentro del nacionalismo. Así, el 13 de abril de 1929, prosiguiendo otro de cuatro días antes, también sobre el padre Moret, primer cronista del reino de Navarra en el siglo XVII, al que había tildado como «el constructor de la historia de Navarra», se termina preguntando: «Pero el padre Moret, al construir el reino de Navarra, creó un nuevo problema, sin él advertirlo: el problema de Navarra en el pueblo vasco; ¿fijó una categoría dentro de otra o al margen de la otra?».

\section{EL VASQUISMO ESPIRITUALISTA DE ELADIO ESPARZA EN SUS COLUMNAS EN DIARIO DE NAVARRA} ENTRE JUNIO DE 1929 Y LA PRIMAVERA DE I93I

El 5 de junio de 1929, siendo todavía secretario municipal de Lesaka, comenzó sus colaboraciones con Diario de Navarra bajo una sección titulada con el mismo nombre de Interpretaciones que la que tenía en La Voz de Navarra. Ese día agradecía «la cortesía» de aquel medio al posibilitar su retorno al mismo. Un año después, en julio de 1930, abandonaría su trabajo de secretario para hacerse cargo de la subdirección de dicho periódico ${ }^{25}$.

Aunque no ha recibido la atención que merece, Esparza fue mucho más importante que el director del periódico, Raimundo García - conocido por los seudónimos de Garcilaso, Ameztia y otros- para la vertebración de los marcos mentales e ideológicos de la derecha navarrista. Desde finales de los años veinte y durante las dos décadas posteriores, los textos de sus columnas diarias en Diario de Navarra, publicados bajo diversos epígrafes —Postales, Friso Rojo, Mi gacetilla, y también otros- tocaron todos los temas importantes para la política y la sociedad navarra. Además de sus tesis en pro de un vasquismo espiritual alternativo al vasquismo político nacionalista que analizamos en este artículo -y que eran mucho más elaborados que los de Garcilaso ${ }^{26}$-, en la cuestión identitaria y político-institucional terminó de perfilar los ejes del llamado navarrismo foral por medio de su concepto de soberanía foral que representaba el abandono definitivo

${ }^{25}$ AML, Libro 26, Libro de Actas de Pleno, 1923-1931, fol. 136v.

${ }^{26}$ Fernández Viguera, 1990. 
del «treintaynueveunismo» y la asunción del «cuarentayunismo», todo ello bajo la refutación del nacionalismo vasco y del estatutismo republicano, así como también del reintegracionismo, tal y como demuestra el éxito de sus posiciones durante el periodo republicano, según vimos en un artículo anterior ${ }^{27}$. Esparza estaba muchísimo más dotado intelectualmente que Garcilaso para pergeñar discursos de conformación sociopolítica y era mucho mejor conocedor de la realidad navarra, globalmente considerada, así como de la audiencia a la que se dirigía. $Y$ supo emitir mensajes desde el periódico del que era subdirector, simultáneamente aceptables y movilizadores, para el mayoritario sector tradicionalista de la opinión pública $-y$ que tenía en el periódico carlista El Pensamiento Navarro su canal propio, pero con un nivel discursivo de menor talla intelectual- y para las élites y las sensibilidades conservadoras que constituían el público original de Diario de Navarra.

Entre junio de 1929 y la primavera de 1930 Eladio Esparza dará repetidas pruebas de su amor al euskera para posteriormente defender un vasquismo espiritualista, que alcanzará su máxima articulación en su novela La Dama del Lebrel Blanco, frente al vasquismo político de los nacionalistas.

Al poco de su incorporación a Diario de Navarra, el 30 de junio de 1929, al hilo del libro Las Casas Vascas de Joaquín de Irízar, afirmó que «la vieja lengua rudimentaria, pulida al uso moderno, puede dar poetas como Satarka, como Jautarkol, como Arregi, como otros, capaces de encarnar el lirismo agudo y caústico de Heine». Asimismo, será el encargado de una sección titulada Lira Vasca en donde traducirá al castellano poesías en euskera de varios autores como Sagartzazu (I de noviembre y 25 de diciembre de 1929), Arrese (16 de febrero de 1930), Jauregi (30 de abril, 29 de mayo de 1930 y 31 de julio), Maruri (3 de julio de 1930), Arregi (28 de diciembre de 1930). El 24 y el 25 de enero de 193I en la sección Poetas Vascos traducirá la poesía Otartxo Utsa de Lizardi. Además de todo ello, el 4 de febrero de 1930 discrepará de Salaverría en relación con la afirmación de este de que el euskera «ha de perecer definitivamente» ante la modernidad, señalando que, aunque ese hecho se produjera, no sería «porque el idioma carezca de posibilidad de adaptación a las nuevas formas de la vida», sino porque el problema radicaba en «el desbarajuste que se palpa entre el pensar y el obrar». Igualmente alabará la gramática vasca de Gavel (25 de agosto de 1929), la obra del padre Larramendi (3I de agosto de 1929), la de Juan Ignacio de Iztueta (4 de septiembre de 1929). Y el 29 de noviembre del mismo año se congratulará de la entrada de Julio de Urquijo en la RAE como representante de la lengua vasca, señalando que «nuestro milenario idioma está de enhorabuena».

\footnotetext{
${ }^{27}$ Mikelarena, 2013.
} 


\section{EL VASQUISMO ESPIRITUAL DE ELADIO ESPARZA}

A partir de la primavera de 1930 presentará su vasquismo alternativo al vasquismo nacionalista. Lo hará casi simultáneamente a sus argumentaciones contra el reintegracionismo foral presentadas en múltiples artículos que publicó entonces $-y$ que estudiamos en un artículo aún en prensa- en un ejemplo de refutación sistemática de los dos pilares básicos del nacionalismo vasco en Navarra.

El 8 de mayo de 1930 argumentó contra el falso foralismo de los nacionalistas y los retó en vasquismo desde su posición de vascoparlante: «Dije hace mucho tiempo que estaba dispuesto a seguir al más valiente e intrépido en vasquismo y navarrismo. Pero en vasquismo ha de ser con quienes me hablen en euskera, no en castellano de mitin». El 3 de junio, al hilo de la Fiesta por la poesía vasca organizada en Rentería por Euskaltzaleak, comentó que, en representación de Navarra, solamente fueron él, María Paz Ciganda y Angel Irigaray, y no «esos vascos que nos dan, un día sí y otro también, el dó de pecho euskeldun en el sabroso castellano y a quienes jamás se les ve en una fiesta vasca». Pedía a estos últimos «que se callen para siempre» en relación con el euskera, idioma «que ni lo sienten ni lo saben».

En otros artículos propugnará un vasquismo lingüísticamente activo. El 10 de junio en Interpretaciones, tras rememorar el mensaje enviado por la Diputación de Navarra a la de Guipúzcoa en 1896 de apoyo a la exigencia del euskera para los maestros de zonas vascoparlantes, Esparza concluía: «La lengua vasca no ha de propagarse ni ha de pulirse con una Real Orden. Si los vascos no se molestan en aprenderla, en hablarla, en enriquecerla ¿para qué los reales decretos?»». El I4 de junio, después de varios párrafos en los que muestra su apoyo al «amplio movimiento a favor de la lengua milenaria» afirmará que «la ley (...) no tiene por qué respetar lo que nosotros no hemos respetado (...). La ley no tiene por qué reconocer un derecho que nosotros hemos sido los primeros en violarlo». En su opinión, siendo necesario cooperar con «las campañas emprendidas», «no todo ha de ser manifestación y envío de tarjetas sino empresa de poner en juego la voluntad para que la lengua sea cosa viva, realidad incorporada a nuestros actos (...) El vascuence requiere ser hablado. Eso es todo».

El I 3 de noviembre de 1930, con ocasión del libro de poesías vascas Eusko Olerkiak, una antología de los poemas premiados en Rentería prologada por Aitzol, recalcó que

mientras los vascos no nos percatemos de que el único renacimiento posible es el renacimiento sentimental, no habrá renacimiento. Podrá haber otra cosa: República, si se quiere; Soviet, si se empeñan. Pero renacimiento vasco, no. Todo renacimiento es obra de la emoción, de esa emoción viva e intensa, que la poesía vierte como agua poderosa que hace mover la conciencia. 


\section{FERNANDO MIKELARENA PEÑA}

Debemos leer a nuestros poetas. Esta es la primera y elemental labor: leer a los poetas.

En sus tesis mencionará en varias ocasiones a Bonifacio de Echegaray. El 24 de enero de 1931 lo citará para subrayar «la diferencia entre los que han colaborado en la cultura vasca con la energía amorosa de quienes la han sentido en su corazón y los que han abusado de ella para menesteres inconfesables». El I I de febrero, al glosar un comentario de aquel jurista y polígrafo vascófilo zumaiarra a una carta de Broussin a Azkue, Esparza indicó: «Un idioma no tiene, en la práctica, más que una solución: hablarlo (...) Pero no hablarlo hasta el límite reducido de las necesidades elementales de la vida, sino hasta la expansión de la necesidad espiritual». A la par, se preguntaba « ¿serviría el vascuence de instrumento adecuado para la cultura nuestra?», subrayando que «es tan fundamental la respuesta a esta pregunta que, según su sesgo, sería una u otra la actitud definitiva para con el eusquera en el sentido de salvarlo como monumento nacional, o de salvarlo como idioma para el trato de gentesı.

Paralelamente enfocará hacia el nulo apoyo de la monarquía navarra hacia el euskera y hacia la españolidad de la misma. El 6 de junio de 1930 afirmó que «a nuestros reyes auténticos les faltó la conciencia de la nacionalidad navarra» y que no elevaron el vascuence «a categoría de lengua oficial» dificultando la interpretación de

que el reino de Navarra fue algo distinto, en esencia, a los demás y con soberanía, surgida del derecho de un pueblo a gobernarse a sí mismo. Pero eso no fue así. Nuestro mayor rey, aureolado de esplendor imperialista, se llamaba a sí mismo Emperador de España.

El 27 de septiembre de 1930, al tratar sobre la circunstancia de que un monje navarro euskaldun fuera el autor de las Glosas de San Millán apuntó que «Ni el Fuero, corazón de nuestra vida, pudo escribirse en euskera» y así «la lengua de Castilla (...) nos prestó el instrumento en que se pudo constatar la razón social de nuestra soberanía».

\section{LA INFLEXIÓN DE LA DAMA DEL LEBREL BLANCO}

Muchas cuestiones vistas en el apartado anterior toman un nuevo giro en la novela La Dama del Lebrel Blanco que Esparza publicó en 1930 en la Editorial Juventud de Barcelona, cuando ya llevaba más de un año como colaborador habitual de Diario de Navarra. Dedicó la novela, que consideró un «relato de una gran aventura malograda en su vuelo», a su amigo el afamado tenor Isidoro Fagoaga, «intérprete afamadísimo de Wagner, (...) tan ignorado en su patria como celebérrimo en el extranjero. Y con él, a su tierra y la mía, la siempre bien amada y dulce tierra del Bidasoa». Ya el 24 de septiembre de 1929 Diario de Navarra 


\section{EL VASQUISMO ESPIRITUAL DE ELADIO ESPARZA}

informó de la cena de homenaje que Esparza y varios bidasotarras brindaron a Fagoaga en un restaurante de Lesaka por la publicación del primero de los discos que iba a editarle la casa Columbia. Y el 6 de mayo de 1930 publicó una entrevista de Esparza a Fagoaga con ocasión del estreno de la ópera Amaya en Buenos Aires que finalizaba recordando los paisajes de la novela: «Y cuando anochece sobre el Bidasoa, evocamos los dos Estella, Milán, Leyre...»».

En efecto, los protagonistas del libro son dos trasuntos de Esparza y de Fagoaga, Ramón de Agesta y Juan Ignacio de Mendizar. Mendizar «vive de sus compromisos artísticos, que le han dado laureles y pesetas». Agesta pretendía «ser novelista». Eran «navarros del país del Bidasoa, vascos de raza y de sentimiento», ambos «solteros» que dedicaban «el verano a excursiones» ${ }^{28}$. Al regresar de Estella y de visitar el pueblo de los ascendientes de Agesta ${ }^{29}$, conocen en Arazuri a Josefa Legarreta, que había vivido siempre en Barcelona y que «había leído y oído hablar un poco»y de ellos y que se marcha en su compañia ${ }^{30}$. En solo unos días en Pamplona ambos amigos consiguen, «con una rapidez pasmosa». «reconstruir el vasquismo en el espíritu de ella» por medio de la música y de la literatura ${ }^{31}$. En esa estancia en la capital navarra Agesta afirma:

Todas estas cosas de vasquismo y navarrismo no tendrán nunca eficacia alguna mientras no se transmita a la plebe la pasión romántica. Yo estoy convencido de que la raza vasca no existe más que en unas cuantas molleras como las que nos han tocado en suerte. Al resto de los vascos la raza les importa un bledo y lo que quieren es buenas carreteras, buena clientela, buenos mercados y buenas recomendaciones para los enjuagues políticos o para los puestos espléndidos ${ }^{32}$.

El desencanto hacia el vasquismo político y la necesidad de vivir el sentimiento vasco de forma individual asoman varias veces en la narración. Agesta comenta en Milán a Mendizar y a Josefa:

Vasconia no puede ser hoy un asunto político. Andando los siglos, acaso lo sea. Hoy, no. Por eso, todo el problema se limita al problema sentimental, a ser custodiado y mimado efusivamente en el corazón, dentro de la gran estructura política del Estado a que se pertenezca

\footnotetext{
${ }^{28}$ Esparza, 1930, p. 25.

${ }^{29}$ Esparza, 1930, pp. 7-17.

${ }^{30}$ Esparza, 1930, p. 63.

${ }^{31}$ Esparza, 1930, pp. 65-66.

32 Esparza, 1930, pp. 69-70.
} 
«porque creo que Vasconia para mí no existe hoy más que en el sagrario interior de nuestro pensamiento ${ }^{33}$. En una conversación con un italiano, Agesta dice de él y de Mendizar ante la pregunta de si «son nacionalistas caracterizados»:

No, nosotros somos vascos, quizás los únicos vascos puros de toda Vasconia. Pero no somos políticos. Políticamente, Vasconia, a mi juicio, no ha sido nunca nación y hoy menos que nunca. Para nosotros, eso nada nos importa. Lo esencial es ser vasco, bien dentro de España, como nosotros, o dentro de Francia, como los ultrapirenaicos.

Ante el reparo del italiano de que «el sentimiento tiende a manifestarse» y «en esa tendencia a la expansión puede originarse el conflicto con el Estado», Agesta explica:

Yo creo que no, si el sentimiento se manifiesta como tal sentimiento. Si políticamente se consiguiera crear una nación entre el Adour y el Ebro (...) nada ganaría Vasconia en su esencia, si dentro de esa nación se hubiera anulado o rectificado el sentimiento vasco ${ }^{34}$.

Asimismo, reconocerá a ese interlocutor que «a los políticos», su nacionalismo «les parecerá literatura, lirismo, nada», igual que a ellos «el nacionalismo de ellos lucha, estrépito, pasión. Le habla a usted un desengañado de la acción política» ${ }^{35}$. En una conversación con el hermano de Josefa, Agesta dice que «hoy no es posible la formación de los pueblos por el idioma, la raza, la costumbre, ni el territorio» ni por «los derechos de la historia».

Para reconquistar un pueblo hay que partir del sentimiento que agrupa las almas y las recoge en un mismo fervor. El sentimiento es patrimonio del espíritu que nadie puede deshacerlo (...). Nosotros hemos tenido territorio, lengua, leyes, pero se quebró el sentimiento y se perdió todo. Ahora es inútil reconstruir el territorio ni las leyes ni la lengua, primero es necesario cazar el alma, perdida en la vasta soledad ${ }^{36}$.

A su juicio, «lo esencial es despertar el sentimiento vasco» y «luego, que cada cual haga lo que quiera» ${ }^{37}$.

A su regreso de Italia, Agesta y Josefa construyen una casa en Leyre pero en su empresa son criticados por vasquistas y por españolistas. Agesta replica a un nacionalista que «tú serás un buen vasco, pero tus hijos ignoran la lengua y la

\footnotetext{
${ }^{33}$ Esparza, 1930, p. 185.

${ }^{34}$ Esparza, 1930, p. 197.

35 Esparza, 1930, p. 197.

${ }^{36}$ Esparza, 1930, p. 253.

${ }^{37}$ Esparza, 1930, p. 252.
} 


\section{EL VASQUISMO ESPIRITUAL DE ELADIO ESPARZA}

historia y las costumbres vascas». Agesta acompaña a su respuesta de una reflexión sobre su rechazo a la oposición entre España y lo vasco porque «ser vasco (...) es procurar» que los vascos «no pierdan el sentimiento específico de su carácter espiritual, la expresión peculiar de su alma» porque España era «la agrupación de naciones» y porque «el contenido vascónico, antes que España, lo vaciaron los propios vascos. Nuestros reyes auténticos no tuvieron conciencia nacional. Se desmembraban de Guipúzcoa, de Alava y de Vizcaya y tendían las fuerzas captadoras hacia la Rioja» ${ }^{38}$.

Por lo demás, la novela recibió el primer premio de la Biblioteca Olave según informó Diario de Navarra el 8 de marzo de 1931, acompañando la noticia de comentarios elogiosos. El II de marzo Navarro de Torres - seudónimo del abogado y posteriormente político de Unión Navarra, Pelayo Moreno- colmó a Esparza de alabanzas por la obra y lo mismo hizo el 26 Fermin de Altobiskar, seudónimo de Eustaquio Echave-Sustaeta, en columna inicialmente publicada en El Noticiero Bilbaíno.

El 17 de abril de 193I Diario de Navarra recogía una crítica de Aitzol - seudónimo del clérigo nacionalista y escritor en euskera y castellano José de Ariztimuño- publicada antes en El Día de San Sebastián que es sumamente elocuente en relación con la honestidad intelectual de aquel y de la relación respetuosa que le unía con Esparza. Aitzol admitía que precisó de dos lecturas de la novela para formarse «un juicio exacto de su valor, más que del literario, del ideológico» porque «una seria preocupación había nacido en nuestra mente». A su juicio, lo que Esparza perseguía «es el descifrar los destinos de Euskalerría (...) No va tras las rutas de la política ni de los negocios. Con fina sensación otea en el ambiente las vibraciones sentimentales del alma vasca, integradas por ansias de arte y belleza». Para Aitzol, «el autor esboza un nacionalismo, por decirlo así, místico, impregnado de arte, belleza y cultura», un enfoque «postergado y relegado ante el esfuerzo de organización, de acción meramente política». Aitzol reconocía que «esto es lo que nos ha hecho meditar, reflexionar. Late en toda la obra un pensamiento sano y robusto». Finalmente concluía que «libros, como este, plantean problemas, que acucien y estimulen el afán de soluciones en el terreno estético nos son provechosos» y que, aunque no se sentía compenetrado con el conjunto de la obra de Esparza, lo felicitaba «por su aportación, que estimamos valiosa, al acervo de la cultura vasca».

Muy diferente era una crítica de Isaac Etxeberria —nombre civil del capuchino Bernardino de Estella - el 8 de agosto de 1931, que desde Argentina subrayaba en el diario Euzkadi el pesimismo atroz de la novela, su obsesión por el

${ }^{38}$ Esparza, 1930, pp. 256-257. 


\section{FERNANDO MIKELARENA PEÑA}

hecho de que el País Vasco está en ruinas y en desolación, y criticaba el desapego del autor hacia los esfuerzos constructivos del nacionalismo vasco. Etxeberria enjuiciaba:

Son muchas las páginas en las que el autor desparrama su veneno (...) Claro es que sus flechas son romas y lo que él cree ser veneno matador es agua fresca de Lesaka. En todas esas páginas vuelve a su tema. Vasconia es asunto sentimental, en manera alguna político. Cuanto se ha hecho por el nacionalismo es puro ruido, sport vasquista.

Al par que mencionaba la radical evolución ideológica de Esparza, tildándolo de antivasco rabioso y monárquico vergonzante, finalizaba diciendo que «Un gran amor españolista circula claro entre los diversos capítulos. La escena lírica de Amayur está mucho menos sentida que la exaltación afectuosa que le inspira España. Es natural. Cada uno se entusiasma con lo que ama».

\section{EL VASQUISMO DE ELADIO ESPARZA EN EL PERIODO REPUBLICANO}

En el periodo republicano Esparza dedicará un aluvión de artículos a la cuestión estatutaria. En primera instancia, auxiliado por Hilario Yaben, se enfrentará al estatuto vasconavarro, tanto en sus dos versiones del año 193। como en la versión finalmente debatida el I 9 de junio de 1932 en la Asamblea de Pamplona, pero también a la posibilidad teórica del estatuto singular para Navarra, que se planteó superficialmente sin ser nunca debatida en serio. Con todo, también se posicionará en contra de otras posibilidades de aumento del autogobierno navarro mediante la aceptación del régimen republicano, polemizando con diversos autores, más allá del verano de $1932^{39}$.

En varias ocasiones, dentro de esas aportaciones o en el contexto de otros textos fuera de ese debate, pregonará su vasquismo y dará claves de su interpretación del mismo. El 24 de abril de 193I en la sección Estampas Forales afirmó la necesidad de diferenciar vascos y navarros, siendo «históricamente los navarros (...) los sucesores auténticos de la estirpe vasca». El 19 de julio del mismo año en Postales aconsejaba que

«precisamente por ser vascos los navarros debemos ser sagaces y oportunos cultivadores de lo antiguo y enamorados de lo moderno, para buscar, dentro de las realidades ineludibles, aquellos contactos con nuestra tierra que sean posibles y que (...) nos den fuerza para seguir reedificando a Navarra, la porción querida que de España nos incumbe. El culto amoroso a lo pasado, sin pasiones reaccionarias, porque sustraerían nuestro esfuerzo a los problemas actuales, nos daría

\footnotetext{
39 Mikelarena, 2013
} 


\section{EL VASQUISMO ESPIRITUAL DE ELADIO ESPARZA}

conciencia de una bien entendida voluntad local, muy deficiente todavía en nuestras vagas actuaciones.

Sobre el carácter vasco de Navarra también incidiría el 19 de diciembre de 1931. Asimismo, el 29 de septiembre de 1931 volvería a expresar sus quejas por haber constatado «demasiadas ausencias» en la celebración de la Fiesta de la Poesía Vasca en Tolosa, a la que Diario de Navarra había dedicado una página entera dos días antes, a la par que se reconocía como de aquellos que sienten «un deseo entrañable por el remozamiento de la categoría espiritual de nuestra tierra».

Diez días más tarde, el 29 de julio de 193 I, publicó en Postales un artículo en euskera, utilizando la variedad dialectal de su comarca nativa, en el que respondía a alguien que le había criticado porque, siendo vascoparlante, nunca escribía en esa lengua, aduciendo que esa acusación no tenía fundamento, puesto que la había empleado en dos o tres ocasiones y que la cuestión radicaba en el carácter castellanoparlante de la sociedad navarra, demostrada por la circunstancia de que en Pamplona ninguna librería vendía libros de poesía en euskera y nadie leía a los poetas vascos. Además, veía un contrasentido en tratar de «euskerizar» en castellano. De cualquier forma, el texto evidencia que Esparza escribía muchísimo mejor en castellano que en euskera.

El jueves 25 de febrero de 1932 será la única ocasión en la que aporte una interpretación de los problemas históricos del euskera para asentarse como idioma socialmente aceptado por la comunidad. En una página entera titulada Vasconia renacentista en la que había un artículo sobre el poeta Lauaxeta y se traducía un capítulo de un libro de Lhande sobre el euskera y la literatura, Esparza se refiere en un texto sobre la lengua vulgar vascongada a que cuando las élites utilizaban el euskera «por obligación o necesidad» «para entenderse con el pueblo», lo castellanizaban «con una prontitud y facilidad pasmosa e irritante». Ello hizo que el pueblo para relacionarse con aquellas «castellanizara su verbo en lo posible», con lo que «entre unos y otros, el euskera se convertía en un patois indecoroso, risible y lamentable». Acompañó a su reflexión de un texto municipal en euskera del siglo XIX plagado de «erderismos» como ejemplo de la carencia de repertorio semántico, «desenfado de sintaxis», «pobreza de los giros», que indicaban «harto claramente el ningún aprecio y la ninguna estima con que trataban al euskera», preguntando por quién era el responsable de todo ello. Admitiendo la conveniencia de la incorporación de elementos extraños para la propia supervivencia del idioma, afirma que «de eso a no cuidar la propia fisonomía, la gracia peculiar del sesgo, la puntuación ortográfica, va mucha diferencia, jva la razón del idioma!». Concluía que mientras «el vulgo no echaba de menos la obra de pulimento, los demás no la utilizaban». 
En esos meses de debate estatutario nunca se refirió a las posibilidades que los diferentes proyectos de estatuto concedían al euskera de cara a su normalización social mediante la cooficialización en la sociedad y a su introducción en la educación en las zonas vascoparlantes. Recordemos que el denominado Estatuto de Estella de 1931, impulsado por carlistas y nacionalistas, implantaba en su artículo 16 la cooficialidad del euskera. Además, el euskera sería el idioma vehicular en la enseñanza en las zonas vascoparlantes, siendo una asignatura más en las zonas castellanoparlantes; que los funcionarios administrativos y judiciales debían ser conocedores del euskera; y que las Diputaciones demarcarían qué territorios serían considerados euskaldunes. Asimismo, en el Estatuto paralelamente proyectado aquel mismo año por las Comisiones Gestoras de las Diputaciones el artículo 16 y el 17 eran idénticos al del otro texto con la salvedad de que en el último se establecía que en las escuelas de las zonas vascoparlantes «se utilizarán para la enseñanza los dos idiomas» con arreglo a las reglas que fijaran las Diputaciones. Por último, tanto el proyecto de Estatuto Vasco-Navarro como el de Estatuto Navarro de 1932 decían lo mismo en su artículo 13 sobre cooficialidad del euskera: derecho de empleo del euskera ante la Justicia y la Administración; en las escuelas de las zonas vascoparlantes se usarían los dos idiomas en la enseñanza según las reglas que fijaran las Diputaciones; la segunda enseñanza y la superior podrían darse en ambos idiomas; los funcionarios administrativos y judiciales deberían ser conocedores del euskera; las Diputaciones remarcarían los territorios euskaldunes.

En ese periodo solamente expresará sus dudas respecto a los efectos del estatuto vasconavarro sobre la lengua. El 7 de abril de 1932 en un artículo de su sección Rodela, titulado «Estatuto, idioma, universalidad», indicará, en contra de las posturas que hablan de que con el Estatuto se busca «la mejora, la difusión, el crecimiento del vascuence», que «el Estatuto no va hacia el idioma sino en señal de acatamiento» y dudará «si el idioma puede ya resurgir hasta codearse con las lenguas de la universalidad». Dos días más tarde, en otro artículo titulado «Independencia e idioma», insistirá en que el vasquismo «no es posible sin saber y conocer y hablar el vascuence que es el signo destacado y el único sin mezcla, del hecho vasco. No comprendo el vasquismo sin el vascuence, más que como gusto turista o como soporte político». Afirmando que «así como no puede darse vasquista sin vascuence, puede darse y se da vascuence sin vasquista», concluirá «el pueblo vasco, independiente, pero sin idioma, dejaría de ser vasco: sería un pueblo independiente» y remitía a la historia la cuestión de que «hemos sido y somos de una parte vasquistas sin vascuence y de otra individuos vascos sin conciencia colectiva vasca». 


\section{EL VASQUISMO ESPIRITUAL DE ELADIO ESPARZA}

De cualquier forma, al igual que no sopesará las posibilidades que las diversas versiones de proyectos de estatuto vasconavarro o navarro a secas ofrecían para la protección y supervivencia de la lengua vasca ${ }^{40}$, y que no chocaban con su vasquismo espiritual sino que enriquecían a este puesto que habrían permitido alfabetizarse a los jóvenes en las zonas vascoparlantes y cultivarlo en un registro culto, nunca se referirá a que la Diputación de Navarra afrontara esa tarea, al menos en parte, con una labor dinámicamente protectora del idioma y que incentivara a que los vascohablantes asumieran una cierta conciencia lingüística. Con lo que ese vasquismo espiritual, carente de cualquier apoyo institucional, serviría de bien poco.

A las reflexiones anteriores sumará el 21 de mayo de 1932 la defensa de la lengua castellana como lengua propia de Navarra también ya que decir «nuestra lengua vasca, nuestra lengua castellana» es decir «dos verdades» $y$ «dos verdades que pueden ir juntas», sacando a relucir al Príncipe de Viana, Huarte de San Juan, Cunchillos, Moret, Malón de Echaide. El 16 de septiembre del mismo año dedicaría otro artículo a Malón de Echaide y a su apología de la lengua castellana en un apartado de su obra La conversión de la Magdalena.

En lo que restaba de República no hemos encontrado demasiados artículos significativos de Esparza en relación con el vasquismo y con la lengua vasca. El 5 de abril de 1932 en su sección Rodela reseñó que en un intermedio de un festival de pelota de niños y jóvenes saliera un grupo de dantzaris con la ikurriña provocando silbidos de parte de la concurrencia, razonando esto porque dicha bandera «tiene una significación política» y porque «el público se percató de la maniobra». "Y es que no se pueden impurificar las cosas, no se pueden mezclar las significaciones, no se puede ni se debe hacer política en todo momento y al hilo de todo pretexto».

El 21 de setiembre de 1934, en otro artículo en la misma sección Rodela sobre la vasquidad de Navarra afirmó, en respuesta a un artículo de La Voz de Navarra, que los navarros se sintieron históricamente

navarros sin género de duda, mas no vascos. Dígase lo que se diga y escueza lo que escueza, el resultado de nuestra historia es ese. No digo que se sintieran antivascos: sencillamente se sintieron navarros. Se sintieron textualmente, naturales del reino de Navarra en la monarquía española.

Pocos días después proporcionaba más explicaciones, aduciendo que

\footnotetext{
${ }^{40}$ Sobre la evolución y sociolingüística de la lengua vasca en Navarra, Erize, 1997.
} 
lógico debiera ser también deducir que Navarra no se sentiría vasca cuando teniendo su idioma vasco peculiar, no lo adoptó en su vida. Pero tampoco dije yo que Navarra fuera antivasca (...). Ni vasca ni antivasca.

Dije sencillamente que Navarra, antes y después de su incorporación a Castilla, se sentía de España, si bien no acerté yo con el matiz de frase exacta para expresar cómo y por qué Navarra sentía el vínculo a España. España no era un reino determinado: ni León, ni Aragón, ni Castilla, reinos tan independientes como el de Navarra. Pero de todos ellos resultaba España.

Sin embargo, el 30 de junio de 1935, en su sección Postales, tras una serie de artículos publicados el 16, el 19, el 26 y el 28 del mismo mes sobre la suspensión del Aberri Eguna, reconoció que uno de los motivos del interés del nacionalismo vasco por Navarra es «la raíz históricamente vasca de los navarros. La veta racial no aparece tan diáfana, tan limpia, tan inconfusa en las otras regiones como aparece en Navarra. En realidad, los vascos somos nosotros». «Pero en Navarra todo esto es chino. El programa nacionalista encontrará siempre en $\mathrm{Na}$ varra un obstáculo invencible: este obstáculo es la sensatez política de nuestro pueblo», provocada porque las dos «fuerzas espirituales» que existen en el territorio navarro con «dos zonas distintas y dos temperamentos distintos» se neutralizan.

Por último, en su obra de 1935 Discurso sobre el Fuero de Navarra4l, de 1935, la única referencia a la vasquidad de Navarra se encuentra al final, en la página XXI, cuando habla de: «cuando el versolari deje de lanzar sus estrofas destartaladas en las plazas recoletas de nuestros pueblos vascos, que sonríen en la lluvia, en el viejo idioma hecho a golpes de sílex y con miel silvestre».

\section{El VASQUismo de Eladio ESPARZA TRAS JULIO DE 1936}

Tras el golpe de Estado de julio de 1936, Esparza publicará repetidamente inflamados artículos de apoyo al bando nacional. En uno de ellos, del I de agosto de 1936, se referirá a la lucha de los combatientes navarros en Guipúzcoa con las tropas golpistas como «una guerra de salvación contra unos forajidos que estaban dispuestos a la más cruel matanza y al terror más espantoso» para terminar pidiendo que la Diputación dejara de subvencionar a la Sociedad de Estudios Vascos por su silencio cómplice ante la muerte de navarros en el frente y por «encubridora del separatismo». También actuará como Delegado de Propaganda de Requetés, tal y como se infiere de que en un artículo sobre el frente guipuzcoano publicado simultáneamente el 8 de agosto en Diario de Navarra y en

\footnotetext{
${ }^{41}$ Esparza, 1935.
} 


\section{EL VASQUISMO ESPIRITUAL DE ELADIO ESPARZA}

Arriba España, constara la firma de dicho cargo en aquel y su nombre y apellidos en este. Asimismo, en el mismo periódico, el I de septiembre se dijo que compartía ese cargo con Francisco López Sanz, director de El Pensamiento Navarro. Participará activamente en mítines en el otoño de 1936 y en el invierno de 19361937 organizados por la Junta Central Carlista de Guerra de Navarra. También será Secretario de la Junta Superior de Educación, encargada de la depuración de los maestros izquierdistas y nacionalistas.

Resulta plausible pensar, por la variedad dialectal y por los giros y expresiones empleadas, que él fue el autor del texto en euskera publicado sin firma en Diario de Navarra de 20 de septiembre titulado «Euskeraz». En él se afirmaba que no hemos sido enemigos de dicho idioma, colmaba al mismo de alabanzas y se animaba a los vascoparlantes a usarlo y a aprenderlo a quienes no lo hablaran. Indicaba, asimismo, que «el vascuence no se va a perder en nuestro pueblo en nuestra gran España» y que «nuestros vascoparlantes no deben tener miedo». Con todo, contraponía a quienes habían manipulado y envilecido el euskera en una conducta ilegítima con quienes, como el autor del texto, lo amaban, así como a sus hablantes. Por último, animaba a los vascoparlantes a gritar en ese idioma «Viva España en nombre de Dios».

Posteriormente, Esparza tratará de aquietar la animosidad de algunos contra las manifestaciones culturales vascas. El 10 de noviembre de 1936 defenderá que los párrocos de la Montaña siguieran predicando en euskera, calificando las críticas a ello de algunos como «una torpeza incalificable», preguntando si «vamos a abominar del vascuence porque algunos lo hayan utilizado para la causa separatista» y afirmando que «nosotros no tenemos por qué vilipendiar lo vasco, de que estamos orgullosos como debe estar de lo que es suyo todo hijo bien nacido». El 12 de febrero de 1937 en su sección Friso Rojo justificará la violencia contra los marxistas y los separatistas por no quedar «margen nacional para los sin Dios y sin Patria-España en la Patria que desea vivir como Dios manda», pero argumentará contra el «sector más o menos extenso de opinantes» para el que «todo cuanto se relaciona con "lo vasco" (lengua, música, costumbres, etc.) supone poco menos que una concesión al adversario, un vivo recelo o, siquiera, una inevitable antipatía». Consideraba que eso es «un error mayúsculo y conviene disiparlo para no incurrir en torpezas lamentables. Ni las ideas ni los sentimientos se extirpan a cuchillo», sobre todo porque se podían suscitar reacciones contrarias. Como solución, planteaba la defensa del vascuence «como sagrada peculiaridad nuestra» para que el separatista se desprenda «del separatismo, para eliminar en su espíritu la idea nociva y absurda de que España es el tirano que aborta los sentimientos de naturaleza, de tradición, de familia».

Hasta dos años más tarde —después de haber sido nombrado en mayo de 1937 miembro del Consejo de Prensa y Propaganda de FET y de las JONS y en 
agosto del mismo año Gobernador Civil de Alava - no hay más opiniones publicadas de Esparza sobre el tema que estamos analizando. El I 8 de marzo de 1939 comentará una noticia aparecida en Diario de Navarra dos días antes sobre la publicación de una orden ministerial que obligaba a la rectificación de «nombres exóticos» como los de carácter vasco, opinando que le parecía «un contrasentido que una persona española no pueda llamarse Miren o Iñaqui» cuando hay tantos apellidos vascos.

En esta misma línea, el 22 de octubre de 1940 tildó de insensato, inexplicable y absurdo «pretender extirpar el separatismo vasco demostrándoles que el vascuence es lengua extranjera» ya que «a quien sea separatista no puede brindársele ocasión más espléndida que el demostrarle nosotros el extranjerismo de su idioma», cuando el vascuence «tiene tanta culpa en la política separatista como pueden tenerlo el plomo de Alcoy y las poesías de Prudencio», siendo indiscutible que «el vascuence se clasifica entre las lenguas de España».

En los años cuarenta, a pesar de ser nombrado académico de la Academia de la Lengua Vasca a propuesta de su presidente Azkue, en abril de 194I, en la primera reunión de la entidad tras la guerra, mantuvo una relación distante con la misma no asistiendo a ninguna reunión. Tampoco mencionó nunca a la institución en la revista Príncipe de Viana de la que fue director desde 1940 a 1955. Una razón de ello pudieron ser sus diferencias con Julio de Urquijo a cuyo homenaje en 1949 no acudió cuando sí lo hicieron altos representantes de la Diputación Foral de Navarra, así como políticos derechistas navarros. De cualquier forma, en la sesión de la Academia del 25 de marzo de 1949 se notificó su dimisión como miembro de la misma aduciendo que estaba saturado de trabajo. No obstante, comunicó que estaría dispuesto a ayudar para que la Academia tuviera una secretaría permanente en Pamplona y para que recibiera ayuda de la Diputación, lo que se concretó en un acuerdo de concesión de 5000 pesetas anuales del 27 de mayo de 1950 y en el apoyo a la celebración el 24 de junio del mismo año en Pamplona del acto de ingreso de Manuel Lecuona como académico, en la que participó el mismo Esparza como director de la revista Príncipe de Viana y en la que el vicepresidente de aquella, el corellano Arellano, hizo un discurso de vasquismo españolista ${ }^{42}$.

En otros artículos defendió los bailes vascos de algunas comarcas de $\mathrm{Na}$ varra alegando que en ellos no había «asomo de nacionalismo» ( 12 de mayo de 1943), repitiendo su juicio positivo sobre los mismos unos años después - I 3 de julio y 4 de noviembre de 1948, en este último caso apelando a la necesidad de

42 Ugarte Muñoz, 2016, pp. 106-109, II6, I38-139, 199-200, 250-25।, 329-332. 


\section{EL VASQUISMO ESPIRITUAL DE ELADIO ESPARZA}

cultivo «afanoso e inteligente» del folklore navarro-. También dedicará columnas elogiosas a Azkue y a los ejemplos de literatura popular vasca que recogió en Navarra (I2 de marzo de 1948 y 13 de noviembre de 195I), así como a Uhlenbeck (6 de febrero de 1952) y a Dechepare y Larramendi y a la cátedra de vascuence que se creó en Salamanca ( 9 de enero de 1946 y 26 y 27 de marzo de 1952). A la par que el 29 de abril de 1948, al hilo del artículo de un inglés en el que a partir del análisis de la sangre vasca se infería que el pueblo vasco es el más antiguo de Europa, afirmaba que al mismo «pertenecemos los navarros», el 20 de septiembre de 1950 criticó la voz relativa al País Vasco de una enciclopedia de la religión católica publicada en Barcelona por usar la palabra Euzkadi, integrando a Navarra, por su significación separatista.

Finalmente, el 10 de septiembre de 1952, al comentar un número de la revista de estudios vascos Zumárraga, publicada en Bilbao, afirmó que «otra vez lo vasco se convierte en tema seductor», "pero los estudios no son políticos, es decir, no se fuerza el tema para encajarlo en testimonio político. Y no cabe duda de que con esta actitud estudiosa, quien gana es el tema». Además de a los contenidos de dicha revista, quizás se refería indirectamente al hecho de que el 12 de diciembre de 1949, a iniciativa del diputado Zubiaur, la Diputación Foral de Navarra acordó reestablecer en Pamplona las clases de vascuence patrocinadas por la misma. Las clases, de iniciación al idioma y adscritas a la Institución Príncipe de Viana, se iniciarían en enero de $\left.195\right|^{43}$.

\section{CONCLUSIÓN}

El vasquismo espiritual era otro de los eslabones de la propuesta navarrista foral-católica propugnada por Esparza junto a su concepto de soberanía foral y su rechazo del estatutismo republicano y del reintegracionismo «treintaynueveunista» -este último juzgado como subsumido en la práctica a partir de 1931 en la vía estatutaria amoldada a la Constitución de la Segunda República-. Además de propugnar un proyecto político -que interpretaba Navarra como un proyecto político diferenciado de otras regiones limítrofes, firmemente engarzado en España y fundamentado en la foralidad, entendida esta según el marco de la Ley de Modificación de Fueros de 1841 -, Esparza también articulaba su propuesta como ideología identitaria en la medida en que conlleva un mensaje de identidad colectiva y de diferencialidad de los navarros, basado principalmente en dos elementos: en la historia, pero, sobre todo, en la medida en que constituye el eje de su propuesta política, en la foralidad. El pasado de Navarra es recreado reinterpretando la conquista de Navarra a la monarquía hispánica en I5 I2 y la

43 Jimeno Jurío, 1996. 
posterior relación con ella hasta $184 \mid$ en términos de pacto entre iguales y depositando en esa circunstancia el eje de la relación con el Estado ${ }^{44}$. Por lo que respecta a la foralidad, concebida con arreglo a la surgida con la ley de $184 \mathrm{I}$, Esparza la esgrime como un signo identitario, a pesar de su carácter ciertamente sui generis en virtud de su naturaleza ciertamente abstracta, naturaleza fácilmente comprobable en el hecho de que la mayoría de los navarros, tal y como el mismo Esparza reconocía en artículos publicados en Diario de Navarra el I y el 2 de abril de 1930 y en su Discurso sobre el Fuero de Navarra de 1935, aunque afirmen que son los fueros nuestro elemento distintivo y de configuración comunitaria, tengan grandes dificultades para definirlos con precisión.

Hay que llamar la atención sobre la circunstancia de que el discurso identitario navarrista sería un caso excepcional dentro del conjunto de los discursos identitarios referidos a comunidades no estatales porque no abundan los ejemplos en que un elemento abstracto como la foralidad sea el núcleo del mensaje. Por lo común, tales elementos nucleares suelen ser de naturaleza lingüística, cultural o religiosa. La fundamentación de la diferencialidad navarra en la foralidad posibilitaba el éxito teórico y práctico del navarrismo por ser aquella un elemento diferencial muy cómodo de asumir por parte de los navarros por cuanto llega de forma automática y no compromete a ningún esfuerzo, y por ser válida y transversal para toda Navarra, configurándola como una realidad única que trasciende las diversidades internas.

Por otra parte, las singularidades de su vasquismo permiten hacer varias apreciaciones. El carácter de vascoparlante y de vascófilo de Esparza lo capacitaba para la refutación de las tesis del nacionalismo vasco más ortodoxo, sobre todo porque le permitía argumentar desde una vasquidad espiritual sobreelevada ante los nacionalistas vascos de Navarra, por lo general no vascoparlantes. Asimismo, al subrayar la pluralidad cultural navarra relativizaba la importancia identitaria del vascuence en relación con Navarra, y al no hacerse eco de la conveniencia de políticas activas de fomento del vascuence, tal y como propugnaban los textos estatutarios de 1931-1932 en sus diferentes versiones, incluida la uniprovincial, extraía a ese elemento de la agenda del debate público y lo confinaba al ámbito de sus hablantes, limitados en número y concentrados en áreas rurales, si bien observados con simpatía por ese vasquismo retórico que no le ofrecía mecanismos de desarrollo. De cualquier forma, el vasquismo espiritual de Esparza habría exigido el cultivo efectivo de la lengua vasca en alguna medida por su parte, así

\footnotetext{
${ }^{44}$ Mikelarena, 2013.
} 


\title{
EL VASQUISMO ESPIRITUAL DE ELADIO ESPARZA
}

\author{
como una reflexión añadida en favor de su desenvolvimiento para ser convin- \\ cente y ser algo más que un argumento de índole negativista para la lucha ideo- \\ lógica.
}

\section{BIBLIOGRAFÍA}

Aznar Munárrz, Cristina, «Esparza Aguinaga, Eladio», en Enciclopedia Auñamendi [en línea], 202I.

Chueca, Jesús P., «José Agerre, euskaltzale eta abertzale baten oroimenez», Geronimo de Uztariz, 3, 1989, PP. 92-96.

Erdozáin, Pilar y Fernando Mikelarena, «Demografía, sociedad y proceso de agrarización: Lesaka entre 1824 y 1930», Sancho el Sabio, 19, 2003, pp. 95-131.

Erize, Xabier, Nafarroako euskararen historia soziolinguistikoa (I 863-1936). Soziolinguistika historikoa eta hizkuntza gutxituen bizitza, Iruñea, Nafarroako Gobernua, 1997.

Esparza, Eladio, La Dama del Lebrel Blanco, Barcelona, Editorial Juventud, 1930.

Esparza, Eladio, Discurso sobre el Fuero de Navarra, Pamplona, Ediciones Príncipe de Viana, 1935.

Fernández Viguera, Silvia, «La ideología social y política de Raimundo García Garcilaso (1903-1929)», Príncipe de Viana, 189, 1990, pp. 2II-262.

Fuster, Joan, Nosotros, los valencianos, Barcelona, Península/62, 1967.

García-Sanz, Ángel, Iñaki Iriarte López y Fernando Mikelarena Peña, Historia del navarrismo (I84 I-I936). Sus relaciones con el vasquismo, Pamplona, Universidad Pública de Navarra, 2002.

Guía de Navarra para 1925-1926. Anuario Administrativo, Agrícola, Bancario, Comercial, Corporativo, Electoral, Industrial, Judicial, de Negocios, Autoridades y Servicios Públicos de la Provincia, Pamplona, Ángel Saiz-Calderón, Editor, 1926.

Iriarte López, Iñaki, Tramas de identidad: literatura y regionalismo en Navarra, 1870-1960, Madrid, Biblioteca Nueva, 2000.

Jimeno Jurío, José María, «La Diputación de Navarra, el Euskera y Euskaltzaindia (1949-1952)», Fontes Linguae Vasconum. Studia et Documenta, 73,1996, pp. 509-5I5.

Jimeno Jurío, José María, Navarra y Vascongadas (1917-1919). Reivindicaciones autonómicas y Reintegración Foral, Pamplona, Pamiela/Udalbide/Euskara Kultur Elkargoa, 2008.

Mikelarena, Fernando, «A propósito del Olentzero. sobre la pervivencia de algunas manifestaciones y costumbres populares en algunos pueblos a través de los siglos», en La tradición de Olentzero en la Navidad de Lesaka y Euskal Herria, ed. Emilio X. Dueñas, San Sebastián, Sociedad de Estudios Vascos, Lankidetzan, 2007, 4I, pp. I0I-II5.

Mikelarena, Fernando, «Navarra: entre el estatuto vasco y un estatuto singular para Navarra», lura Vasconiae: Revista de Derecho Histórico y Autonómico de Vasconia, 10, 20I3, pp. 395-459.

Mikelarena, Fernando, «El debate sobre la Reintegración Foral y sobre su modo de implementación en Navarra en 1918-1919. La postura historicista de los fueristas radicales del carlismo», Historia Constitucional: Revista Electrónica de Historia Constitucional, 20, 2019, pp. 623-657.

Moreda de Lecea, Carlos, «Don Mateo Múgica Urrestarazu (Antecedentes, pontificado en Pamplona y algunos aspectos de su pontificado en Vitoria)», Excerpta e Dissertationibus in Sacra Theologia, XXI, n. 7, 1992, pp. 522-638.

Osés Larumbe, Elena, «“La Voz de Navarra”, un periódico vasquista. Sus primeras campañas, 1923-193 I», Príncipe de Viana, 184, 1988, pp. 4I5-435.

Ugarte Muñoz, Antón, Euskararen historia soziopolitikorako: Espainiako Gerra Zibilak zauritutako Euskaltzaindia (1936-1954), Donostia, Universidad del País Vasco, 2016. 